\title{
Crack-Fiber Interaction in SiC Fiber-Reinforced Glass Matrix Composite
}

\author{
Kenichiro SEKINE and Yutaka KAGAWA* \\ Graduate School, The University of Tokyo, 7-22-1, Roppongi, Minato-ku, Tokyo 106 \\ *Institute of Industrial Science, The University of Tokyo, 7-22-1, Roppongi, Minato-ku, Tokyo \\ $\mathrm{SiC}$ 繊維強化ガラスにおけるクラックー繊維間の相互作用 \\ 関根謙一郎・香川 豊* \\ 東京大学大学院, 106 東京都港区六本木 7-22-1 \\ *東京大学生産技術研究所, 106 東京都港区六本木 7-22-1
}

106

[Received November 27, 1991; Accepted December 19, 1991]

\begin{abstract}
Interaction between fiber and glass matrix has been observed during crack bridging process in a continuous fiber-reinforced glass matrix composite. The crack growth of the matrix was strongly affected by the presence of the fiber. Crack bowing was clearly recognized when the crack front approached the fiber. Complex stress field caused the rough surface of the matrix crack around the fiber instead of smooth surface as it appears in the general fracture of the glass matrix. The result also indicated a possibility of toughness increase by the crack bowing process.
\end{abstract}

Key-words : SiC fiber-reinforced glass matrix composite, Crack-fiber interaction, In situ observation, Matrix crack propagation, Crack bowing, Weak-bonded interface

\section{Introduction}

Studies have shown that the fracture of fiber-reinforced brittle matrix composite starts from the matrix phase. The crack in the matrix approaches the fiber after the fracture of the matrix. Crack bowing, debonding of an interface, and/or fracture of the fiber are candidate behavior which occurs during the crack growth. ${ }^{1)}$ Michalske and Hellmann ${ }^{2)}$ reported an interaction between $\mathrm{Al}_{2} \mathrm{O}_{3}$ fiber and crack of glass matrix having strong fiber-matrix bonding. However, weak interface is generally required when we regard crack bridging mechanism as a toughening of brittle materials. The interfacial mechanical condition for the crack bridging ${ }^{3), 4)}$ is given by:

$$
G_{\mathrm{Ic}}^{\mathrm{i}}<\frac{\zeta E_{\mathrm{m}}}{4 \pi\left(E_{\mathrm{f}}+\zeta E_{\mathrm{m}}\right)\{Y(\alpha)\}^{2} \xi\left(1-v_{\mathrm{f}}^{2}\right)} G_{\mathrm{Ic}}^{\mathrm{f}}
$$

and

$$
\zeta=\frac{1}{f-1}, \quad \xi=\frac{1}{\sqrt{f}-1}
$$

where $G_{\text {Ic }}^{\mathrm{i}}$ is mode II critical energy release rate of the interface, $G_{\mathrm{I}}^{\mathrm{f}}$ is mode I critical energy release rate of the fiber, $f$ is the volume fraction of fiber, $Y$ $(\alpha)$ is the shape factor of the crack, $E_{\mathrm{f}}$ and $E_{\mathrm{m}}$ are the Young's moduli for the fiber and the matrix respectively; $v_{\mathrm{f}}$ is the Poisson's ratio of the fiber. The report of Michalske and Hellmann ${ }^{2}$ deals with the condition of $G_{\mathrm{II}}^{\mathrm{i}}>G_{\mathrm{Ic}}^{\mathrm{f}}$ because the crack propagation occurred with fracture of fibers.

The crack-fiber interaction under the condition of $G_{\text {II }}^{\mathrm{i}}<G_{\text {Ic }}^{\mathrm{f}}$ seems very important to understand the toughening mechanism. However, details of the crack-fiber interaction behavior, especially in the weak-bonded interface, are not well understood due to lack of experimental evidence. In this study, in situ observation of the crack-fiber interaction behavior has been carried out using $\mathrm{SiC}$ fiber-reinforced glass model material.

\section{Experimental procedure}

$\mathrm{SiC}$ fiber, whose diameter was $140 \mu \mathrm{m}$ supplied by Textron ${ }^{\circledR}$, was used as a reinforcement. The $\mathrm{SiC}$ fiber was sandwiched with a uniform spacing between soda-borosilicate glass (Corning Glass Works, Code \#7740) plates of $2 \mathrm{~mm}$ in thick. Then, the sandwiched fiber and the glass plates were hot-pressed in vacuum. The hot pressing temperature and time, respectively, were $1023 \mathrm{~K}$ and $1.8 \mathrm{ks}$. After the hotpressing, the composite was allowed to furnace cool. The interfacial critical debonding energy release rate at a tip of debond front and the interfacial shear sliding stress of the composite were $0.02 \mathrm{~J} / \mathrm{m}^{2}$ and $10 \mathrm{MPa},{ }^{5)}$ respectively in the stated processing condition. This interfacial shear mechanical condition was estimated enough for the crack bridging (Eq. (1)).

TCB (Tapered Cantilever Beam) specimens were cut from the hot-pressed monolayer type composites. Shape, dimension, and fiber location of the specimen are shown in Fig. 1. Fracture experiment was carried out with a specially-designed hard fixture under in situ observation of an optical microscope. ${ }^{6)}$ The applied load was increased manually with a stepwise mode which allows observation of the slow crack growth behavior. Figure 2 shows an appearance of the specimen mounted on the fixture. The crack growth behavior was continuously monitored and the image was stored to VTR.

After the fracture experiment, the specimen was forced to separate. Then the fracture surface was observed to investigate traces of the crack-fiber interac- 


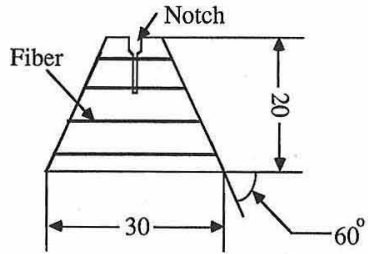

(in $\mathrm{mm}$ )

Fiber :SiC(CVD) [Textron;SCS-6]

Matrix :Glass [Pyrex;CGW-\#7740]

Fig. 1. Geometry and dimension of TCB specimen.
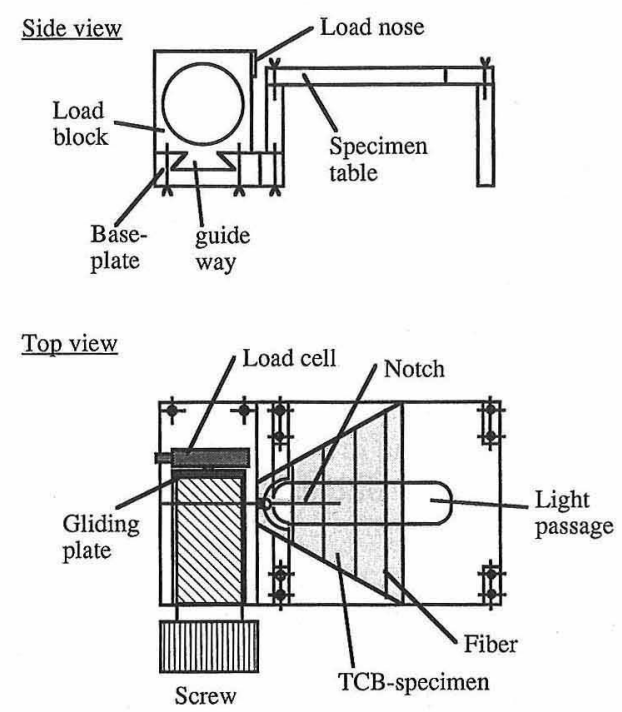

Fig. 2. Typical appearance of TCB specimen mounted on the loading fixture.

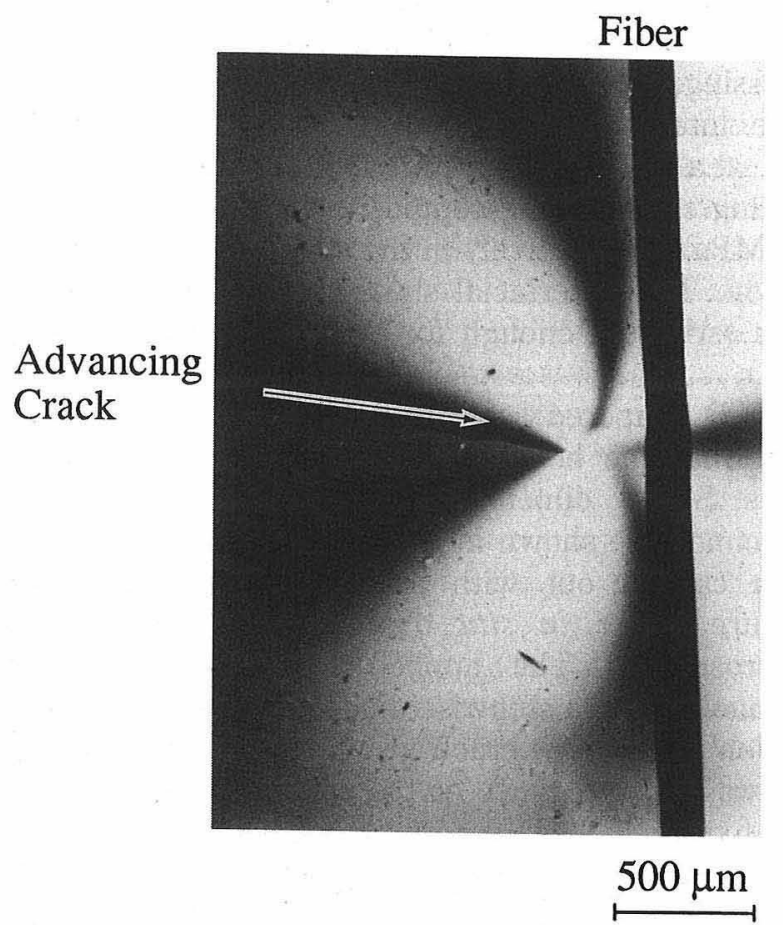

Fig. 3. Polarized transmission optical micrograph of the composite during crack propagation. tion around the fiber by the scanning electron microscope.

\section{Results and discussion}

\subsection{Experimental evidence}

Figure 3 shows a typical appearance of the crack growth behavior in the matrix by using photo-elasticity. Bright area in the photograph is a detected stress field. The result of photo-elasticity suggested when the crack front is far from the fiber, the crack tip stress field was purely mode I. Therefore we assumed the loading condition was purely mode I. Figure 4 shows a typical series of photographs dur-

(a)

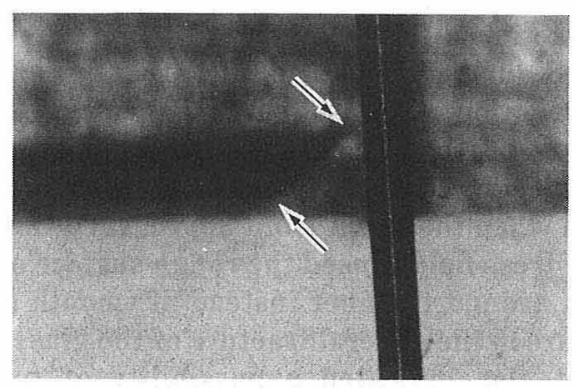

(b)

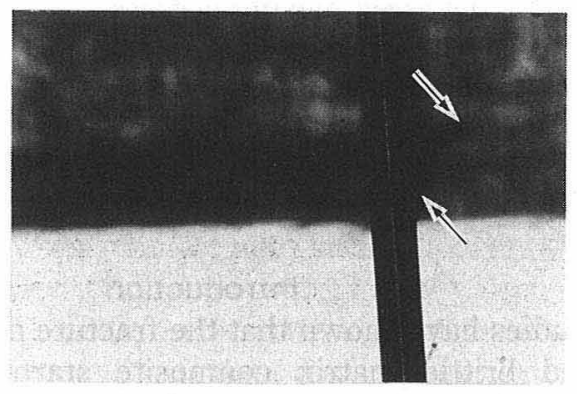

(c)

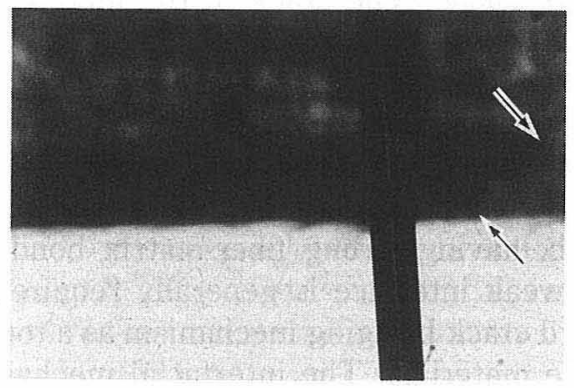

(d)

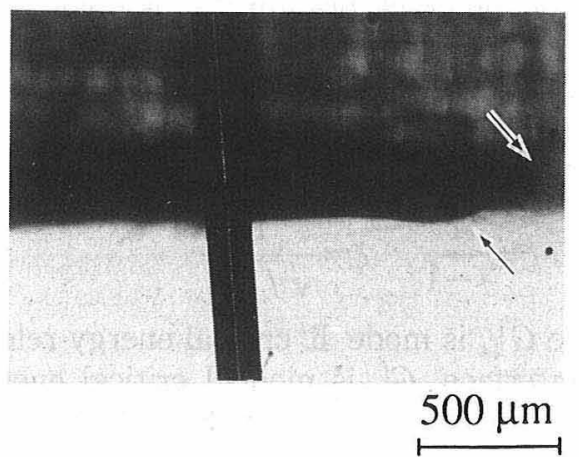

Fig. 4. Series of photographs (reflective light mode) shows crack-fiber interaction during crack passed fiber without fracture of fiber. 
ing fracture experiment. When the crack in the matrix approached to the fiber, crack front bowing was clearly recognized. The amount of crack bowing increased with decreasing the distance between crack front, defined in Fig. 5, and fiber surface. Such interaction of the crack front with a second-phase particle has been reported by several investigators. ${ }^{7)-9)}$

SEM photographs of matrix fracture surface around the fiber are shown in Fig. 6. As shown in these photographs, the crack-fiber interaction was

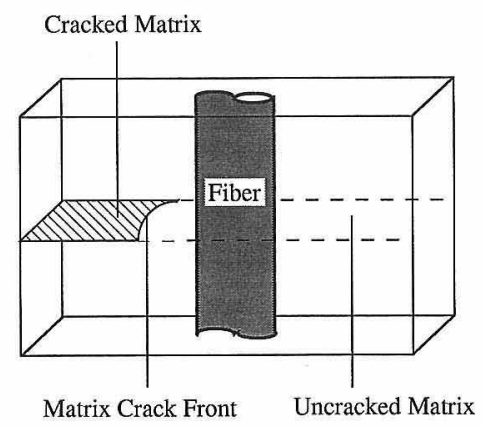

Fig. 5. Definition of crack front.

(a)

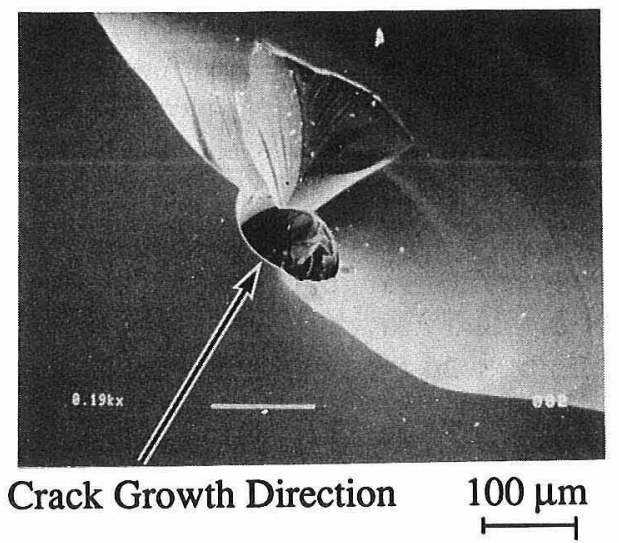

(b)

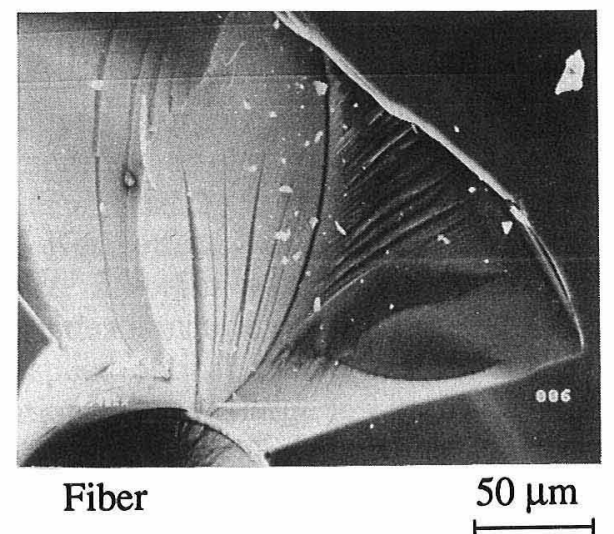

Fig. 6. SEM photographs of fracture surface around the fiber (a) and its higher magnification (b). Crack spread from bottom to top in photographs. clearly recognized. In this case, bridged fibers were carefully fractured by bending force and the specimen was separated into two pieces to obtain fracture surface after the experiment. The fracture surface of the matrix around the fiber was complex and the result suggested the change of fracture mode in the matrix when the crack passed away fiber.

\subsection{Modeling of crack propagation}

Schematic drawing of crack growth process is shown in Fig. 7. With approaching the crack front to the fiber surface, the crack front bows around the fiber (Fig. 7 (a)). When the center of the crack front approaches the fiber-matrix interface, the crack bowing approaches the maximum value. This behavior is explained to be stress intensity reduction. Here the stress intensity exists on the differences of elastic modulus between fiber $\left(E_{\mathrm{f}}\right)$ and matrix $\left(E_{\mathrm{m}}\right)$. Pacella and Erdogan ${ }^{10)}$ explained the effects of elastic modulus mismatch on the crack growth behavior in the matrix assuming cylindrical fiber and surrounded matrix. Their analytical result showed clearly the possibility of crack bowing. Similar bowing behavior was observed in this experiment. Then the matrix crack front at the both sides of the composite join together again leaving an uncracked matrix behind the fiber (Fig. 7(b)). The matrix at the unbroken area finally fractures under complex stress field. The fracture surface shown in Fig. 6 reflects this fracture process of the matrix. More detailed observation

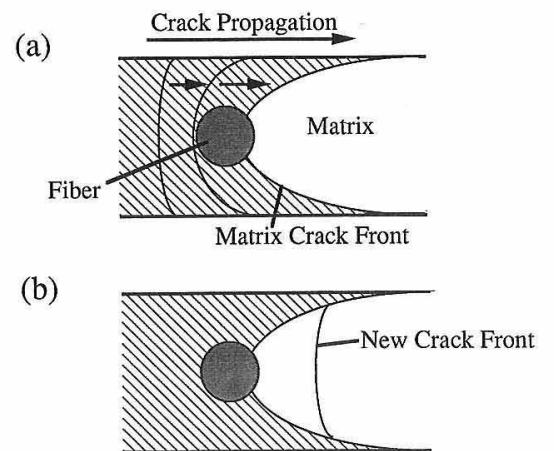

(c)

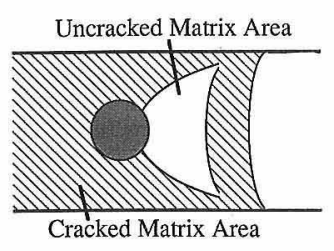

(d)

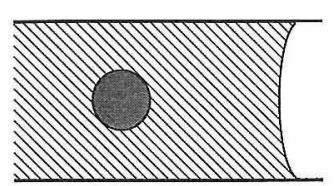

Fig. 7. Schematic drawing of crack-fiber interaction process. Crack propagates from left to right in the figure. Crack front in the matrix bows around the fiber (a). Then the crack fronts at both sides of fiber join together (b), and new crack front spreads leaving an uncracked area (c). Finally the unbroken matrix fractures (d). 
should be required to make an inquiry into the fracture of the remained unbroken matrix.

\section{Concluding remarks}

Crack-fiber interaction has been studied experimentally during the crack growth in the SiC fiber-reinforced glass matrix composite. The experimental observation showed that the crack bowing and complex fracture in the matrix occurred during crack propagation in continuous fiber-reinforced brittle matrix composite. The toughness of the matrix is not uniform. The contribution of the fibermatrix interaction should be considered in the process of bridging.

\section{References}

1) Y. Kagawa and T. Kishi, "Toughening Mechanism of FiberReinforced Ceramic Matrix Composites", in Advanced Com- posite Materials, New Materials, Applications, Processing, Evaluation and Databases, Ed. by C. Bathias and M. Uemura, SIRPE Publishers, Paris (1990) pp. 44-53.

2) T. A. Michalske and J. R. Hellmann, J. Am. Ceram. Soc., 71, 725-31 (1988).

3) K. Sekine and Y. Kagawa, "Effects of Residual Stress and Frictional Sliding on R-Curve Behavior in Fiber-Reinforced Ceramics", Fracture Mechanics of Ceramics, Vols. 9 and 10, Plenum (in press).

4) K. Sekine and Y. Kagawa, To be contributed.

5) K. Honda and Y. Kagawa, Unpublished work.

6) K. Ahlborn, Y. Kagawa and A. Okura, Script. Metal. et Mater., 24, 1063-68 (1990).

7) F. F. Lange, Phil. Mag., 22, 983-92 (1970).

8) A. G. Evans, Phil. Mag., 26, 1327-44 (1972).

9) A. Kelly, "Fibre Reinforcement of Brittle Matrices", Proc. Seminar held at the Joint Res. Center, Ispra Establishment, Italy (1982) pp. 113-29.

10) A. H. Pacella and F. Erdogan, Int. J. Solids Struct., 10, 80719 (1974). 